JOURNAL OF PERIODONTAL RESEARCH doi:10.1111/j.1600-0765.2009.01244.x

\title{
Gingival crevicular fluid can degrade Emdogain and inhibit Emdogain-induced proliferation of periodontal ligament fibroblasts
}

Laaksonen M, Salo T, Vardar-Sengul S, Atilla G, Han Saygan B, Simmer JP, Baylas H, Sorsa T. Gingival crevicular fluid can degrade Emdogain and inhibit Emdogain-induced proliferation of periodontal ligament fibroblasts. J Periodont Res 2010; 45: 353-360. (C) 2009 The Authors. Journal compilation (C) 2009 Blackwell Munksgaard

Background and Objective: Emdogain ${ }^{\circledR}$ (EMD), consisting mostly of amelogenin, is used in periodontal therapy to regenerate lost connective tissue. Emdogain is applied onto periodontally affected root surfaces, where it becomes exposed to proteolytic enzymes. In this study, we aimed to find out whether gingival crevicular fluid or matrix metalloproteinases (MMPs) could degrade EMD, and whether this degradation has consequences for in vitro cell proliferation.

Material and Methods: We studied the effects of 156 gingival crevicular fluid samples collected from subjects with different stages of periodontal disease and from healthy control subjects and the effects of MMP-1, -2, -8, -9, -13 and -14 on the degradation of EMD using EMD-embedded zymography. The effects of gingival crevicular fluid with or without EMD and the effects of amelogenin on the proliferation of cultured periodontal ligament fibroblasts were studied by cell proliferation enzyme-linked immunosorbent assay kit.

Results: Degradation of Emdogain induced by gingival crevicular fluid was greater in samples from all stages of periodontal diseases compared with healthy control samples. Of the MMPs studied, only MMP-2 and MMP-8 showed limited EMDdegrading activities. One hundred micrograms per millilitre of EMD increased proliferation of periodontal ligament fibroblasts on average by $24 \%$ (confidence interval $0.60-0.64$ ) and at $200 \mu \mathrm{g} / \mathrm{mL}$ by $30 \%$ (confidence interval $0.62-0.68$ ) compared with control fibroblasts (confidence interval 0.48-0.52). However, gingival crevicular fluid $(10 \mu \mathrm{g} / \mathrm{mL})$ together with $100 \mu \mathrm{g} / \mathrm{mL}$ EMD induced the proliferation only by $6 \%$ (confidence interval $0.51-0.55$ ) and with $200 \mu \mathrm{g} / \mathrm{mL}$ EMD by $12 \%$ (confidence interval $0.54-0.58$ ). Amelogenin at $200 \mu \mathrm{g} / \mathrm{mL}$ decreased the proliferation of periodontal ligament fibroblasts by $54 \%$ (confidence interval $0.22-0.25)$.

Conclusion: We suggest that diseased gingival crevicular fluid containing various proteases leads to degradation of EMD and decreased proliferation of periodontal ligament fibroblasts.

Timo Sorsa, Research Laboratory, Biomedicum Helsinki, Institute of Dentistry, PO Box 63, University of Helsinki FIN-00014, Helsinki, Finland

Tel: +358407374240

Fax: +358919125371

e-mail: timo.sorsa@helsinki.fi

Key words: Emdogain; amelogenin; gingival crevicular fluid; periodontitis; proliferation; matrix metalloproteinase

Accepted for publication June 15, 2009 
The enamel matrix derivative Emdogain ${ }^{\circledR}$ (EMD) is a commercially available tissue extract preparation of porcine enamel origin. Over 10 years ago, it was suggested that this extract can induce new cementum and bone formation in periodontal defects in monkeys (1). Numerous studies since then have shown that EMD is clinically useful in promoting periodontal regeneration, including the restoration of alveolar bone, cementum and collagenous ligaments (2,3). Emdogain has been widely used in periodontal therapy, but the mechanisms of action and the exact composition of the product are not completely clear. It has been proposed that EMD can mimic and modify natural root development and thereby enhance regeneration (4). The predominant compound of EMD is amelogenin $(>90 \% ; 5)$. In spite of amelogenin not being a growth factor, EMD possesses a number of growth factor-like effects. Emdogain has also been found to be more effective than amelogenin in enhancing fibroblast proliferation together with other cellular functions (6,7). Many studies have aspired to identify various growth factors in EMD, with varying results (8-13). Kawase et al. $(11,12)$ and later Suzuki et al. (13) found the presence of transforming growth factor (TGF)- $\beta 1$ or TGF- $\beta$-like substances in EMD. Emdogain has been documented also to contain a few other cytokines. These include a bone morphogenetic protein (BMP)-like growth factor, which belongs to the TGF- $\beta$ family, and bone sialoprotein-like molecules $(13,14)$, which have also been suggested to be the main functional components of EMD $(6,11,13)$.

Periodontal inflammation is characterized by increased apical proliferation of gingival sulcular epithelial cells together with increased activity of proteolytic enzymes in gingival tissue and gingival crevicular fluid (15-17). Matrix metalloproteinases (MMPs) and matrix-degrading serine proteinases have been shown to be the main mediators of pathological tissue destruction in periodontitis (18-20). These proteinases, in particular MMPs, can degrade most, if not all, extracellular matrix and basement membrane components of perio- dontium (19-22). In periodontal treatment, a full-thickness flap procedure is used to apply the EMD in the deepest periodontal pockets and in contact with periodontally exposed root surfaces. Detectable amounts of EMD remain at the site of application on the root surface for at least $2 \mathrm{wks}$, allowing the product to be exposed to various proteolytic enzymes present in periodontal connective tissue during periodontal disease and also during surgical wound healing (23). These enzymes, produced by the cells of connective tissue and by the sulcular and attached epithelium of gingiva, are also secreted in gingival crevicular fluid $(19,20)$.

In this study, we investigated the effects of gingival crevicular fluid, collected from patients with different stages of periodontal disease and from healthy control subjects on EMD degradation. Our hypothesis was that proteinases in gingival crevicular fluid could degrade EMD. Furthermore, we aimed to find out whether this degradation could be produced by MMPs. We also studied the effects of gingival crevicular fluid on EMD-induced proliferation of periodontal ligament fibroblasts to find out whether the degradation has any consequences in vitro.

\section{Material and methods}

\section{Subjects}

This study was approved by the Ethics Committee of the Ege University, Izmir, Turkey, and written informed consent, in line with Helsinki Declaration, was obtained from each subject. A total of 80 subjects ( 35 male, 45 female) were recruited from the Department of Periodontology, School of Dentistry, Ege University, İzmir, Turkey. Complete medical and dental histories were obtained from all subjects. Subjects were excluded if they had a history of systemic diseases and had used antibiotics and/or antiinflammatory drugs within the last 3 mo or had received periodontal treatment within the last 6 mo. There were both smokers and non-smokers in all groups, equally distributed.

The subjects were selected according to the clinical and radiographic criteria proposed by the 1999 International World Workshop (24). The healthy control group included 13 periodontally healthy females and seven males (aged 15-61 years), with no clinical evidence of gingivitis [papillary bleeding index (25) close to 0], no radiographic evidence of bone loss and no probing depths $>3 \mathrm{~mm}$. The gingivitis group included nine females and 11 males (aged 15-49 years) with bleeding on probing at any site and no radiographic evidence of bone loss (25). The chronic periodontitis group included nine females and 11 males (aged 4063 years), who had at least four sites with a probing depth of $\geq 6 \mathrm{~mm}$ and attachment loss of $\geq 4 \mathrm{~mm}$ at the same site. Diagnosis of chronic periodontitis was made by correlating the clinical attachment loss with plaque levels. The aggressive periodontitis group included subjects with localized aggressive periodontitis (9 females and 1 male; aged 1938 years) or generalized aggressive periodontitis ( 5 females and 5 males; aged 18-38 years). The localized aggressive periodontitis patients exhibited characteristic bone loss localized on the first molars and/or incisors, clinical attachment loss $\geq 4 \mathrm{~mm}$ in at least two permanent molars or incisors (at least one first molar affected) and up to two additional teeth, and minimal inflammation and plaque in areas other than those sites with active disease. Generalized aggressive periodontitis patients showed generalized clinical attachment loss of $\geq 4 \mathrm{~mm}$ on eight or more teeth; at least three of those were other than central incisors or first molars.

\section{Gingival crevicular fluid samples}

A total of 156 gingival crevicular fluid samples were collected from 80 subjects, with 20 subjects in each group. In all study groups, mesial approximal surfaces of two non-adjacent teeth were selected as gingival crevicular fluid sampling sites. In the chronic periodontitis and aggressive periodontitis groups, gingival crevicular fluid samples were collected from two approximal sites with $\geq 6 \mathrm{~mm}$ probing depth and $\geq 4 \mathrm{~mm}$ clinical attachment loss. Gingival crevicular fluid samples in the gingivitis group were collected 
from two sites with bleeding upon probing and $\geq 2 \mathrm{~mm}$ probing depth. In the healthy group, gingival crevicular fluid samples were taken from two sites with $\leq 3 \mathrm{~mm}$ probing depth and without bleeding upon probing. Prior to gingival crevicular fluid sampling, supragingival plaque was removed from the interproximal surfaces using a sterile curette. These surfaces were gently air-dried and isolated with cotton rolls. Gingival crevicular fluid samples were collected by inserting filter paper strips (Periopaper; ProFlow Inc., Amityville, NY, USA) for $30 \mathrm{~s}$. During this process, care was taken to avoid mechanical injury, and strips contaminated with blood were discarded. Gingival crevicular fluid volume was estimated (Periotron 8000; ProFlow Inc.), and strips were placed into a sterile polypropylene tube prior to freezing at $-40^{\circ} \mathrm{C}$. The study groups were blinded from the authors who did the in vitro assays.

\section{Reagents}

Lyophilized Emdogain and Emdogaingel $^{\circledR}$ were kindly provided by the manufacturer (Straumann, Basel, Switzerland, previously Biora AB, Malmö, Sweden), dissolved in phosphate-buffered saline stock solution $(2 \mathrm{mg} / \mathrm{mL})$ and kept at $4^{\circ} \mathrm{C}$. Recombinant pig amelogenin (rP172) was expressed in Escherichia coli strain codon plus BL21(DE3), and isolated as described previously (26). The bacteria expressing rP172 were pelleted, resuspended in $4 \mathrm{M}$ guanidine $\mathrm{HCl}(15 \mathrm{~mL}$ per $500 \mathrm{~mL}$ of culture), sonicated, and diluted with six volumes of ice-cold $0.5 \%$ formic acid. Cellular debris was pelleted by centrifugation at $4^{\circ} \mathrm{C}$ for 10 $\min (15,900 \mathrm{~g})$. The supernatant was raised to $20 \%$ saturation with ammonium sulfate and incubated overnight at $4^{\circ} \mathrm{C}$. Following centrifugation, the pellet was resuspended in ice-cold $0.5 \%$ formic acid. The supernatant was raised to $20 \%$ saturation by the addition of ammonium sulfate and incubated overnight at $4^{\circ} \mathrm{C}$. The amelogenin was pelleted by centrifugation and resuspended in ammonium chloride $(0.05 \%, \mathrm{pH} 9-10)$ and passed over a phenol column $(\mathrm{A}=0.05 \%$
$\mathrm{AmCl} ; \quad \mathrm{B}=80 \% \quad$ acetonitrile + buffer A). The rP172 peak was lyophilized, resuspended in $0.05 \%$ trifluoroacetic acid (buffer C) and injected onto a preparative reverse-phase (C18) column. The amelogenin was eluted with buffer D (buffer C $+60 \%$ acetonitrile) with a gradient of 40 $80 \% \mathrm{D}$ in $185 \mathrm{~min}$. The amelogenin fraction was lyophilized and stored at $-20^{\circ} \mathrm{C}$. The concentrations of 100 and $200 \mu \mathrm{g} / \mathrm{mL}$ EMD and amelogenin used in this study were selected based on our previous publication (27).

\section{Emdogain degradation assays with gingival crevicular fluid and MMP samples}

In order to detect EMD-degrading enzymes in gingival crevicular fluid, the gingival crevicular fluid samples were dissolved in TNC buffer (50 mM Tris, $0.2 \mathrm{M} \mathrm{NaCl}$ and $\left.1 \mathrm{~mm} \mathrm{CaCl}_{2}, \mathrm{pH} 7.8\right)$, and the same volume ( $15 \mu \mathrm{L}$ per well) of each of the 156 gingival crevicular fluid samples was loaded onto EMDembedded zymography. Several different EMD concentrations as well as both lyophilized EMD and EMD-gel were first tested to produce as clear and highquality gels as possible. Emdogain-gel ( $9 \mathrm{mg} / \mathrm{mL}$ ) embedded in the $11 \%$ SDSPAGE, instead of normally used gelatin (28), was selected to be used in these studies. We also aimed to compare the degradation profile caused by gingival crevicular fluid with the degradation profile caused by MMPs. Therefore, recombinant human MMP-1, -2, -8, -9, -13 and -14 (MMP-8: Chemicon, Termecula, CA, USA; MMP-2, -13 and -14: Invitek, Berlin, Germany; MMP-1 and -9: Calbiochem, San Diego, CA, USA) were loaded (200 ng in $3 \mu \mathrm{L}$ per well) onto a separate EMD-embedded gel. After electrophoresis, the gels were washed twice with $2.5 \%$ Trixon X-100 buffer to renature the gelatinases. Gels were then incubated in TNC buffer for $72 \mathrm{~h}$ at $37^{\circ} \mathrm{C}$. Gels were stained with $0.5 \%$ Coomassie Brilliant Blue R-250. The intensities of separate bands were scanned and measured quantitatively using optical densitometry and QUANTITY ONE software (Bio-Rad Model GS-700 Imaging Densitometer; BioRad, Richmond, CA, USA).

\section{Proliferation assay}

Since EMD has been shown to stimulate proliferation of periodontal ligament fibroblasts $(8,29-34)$, we aimed to study the effect of gingival crevicular fluid-induced degradation of EMD on the proliferation of periodontal ligament fibroblasts. Furthermore, the effect of recombinant amelogenin protein, which is the main compound of EMD, was studied. For the proliferation assay, human periodontal ligament fibroblasts were used. The cells were obtained from intact premolars of a healthy young male patient, by a technique described earlier (35), and cultured at $37^{\circ} \mathrm{C}$ in a humidified atmosphere in medium containing (per $100 \mathrm{~mL}$ ): $90 \mathrm{~mL}$ Dulbecco's modified Eagle's medium, $10 \mathrm{~mL}$ fetal calf serum, 100 units $/ \mathrm{mL}$ penicillin, $100 \mu \mathrm{g} /$ $\mathrm{mL}$ streptomysin and $250 \mathrm{ng} / \mathrm{mL}$ Fungizone $^{\circledR} \quad$ (all supplements were from Life Technologies, Paisley, UK). The assay was carried out as previously described (36). Briefly, the cells (passage 7) were plated at a density of 5000 per well $(n=6)$ and allowed to attach and grow overnight. The gingival crevicular fluid samples dissolved in TNC buffer were pooled from all diseased and healthy samples and sterile filtered before adding $10 \mu \mathrm{L}$ per well with or without EMD (100 and $200 \mu \mathrm{g} /$ $\mathrm{mL})$. Recombinant amelogenin (100 and $200 \mu \mathrm{g} / \mathrm{mL}$ ) was used without gingival crevicular fluid. After $48 \mathrm{~h}$ incubation, the proliferation of periodontal ligament fibroblasts was determined with commercial Cell Proliferation ELISA, BrdU kit (Roche Diagnostics, Mannheim, Germany), where bromodeoxyuridine (BrdU) incorporation into newly synthesized DNA was measured in proliferating cells using an ELISA reader at $450 \mathrm{~nm}$.

\section{Statistical analysis}

Analysis of variance models were used to estimate the effects of experimental substrates on various in vitro outcomes. The results are presented as relative comparisons of means between relevant treatment groups, expressed in terms of fold change or percentage from a given baseline, together with 
the $95 \%$ confidence intervals (CI). Confidence intervals were calculated with the Web-based Texas A\&M University's Confidence Interval Calculator (http://www.stat.tamu.edu/ jhardin/applets/index.html). Following the recommendations on statistical presentation in medical journals, we prefer to use confidence intervals in expressing statistical uncertainty instead of 'significance' testing (37).

\section{Results}

\section{Emdogain degradation assays}

The zymography with EMD-embedded gels revealed that the gingival crevicular fluid can degrade EMD (Fig. 1A). The degradation depended on the state of periodontal disease, with markedly more degradation and a wider range of molecular weights being observed in gingival crevicular fluid from periodontitis patients than in healthy gingival crevicular fluid. The analyses were carried out at the most degraded sites at 97, 50 and $37 \mathrm{kDa}$. The degradation was statistically more significant in all the disease states (Fig. 1B-D). At a molecular weight of $97 \mathrm{kDa}$, the 'EMD-lysis' in chronic periodontitis was on average 5.4-fold (mean intensity value 0.85 ; CI $0.65-$ $1.05)$, in aggressive periodontitis 2.2fold (mean 0.40, CI $0.22-0.49$ ) and in gingivitis 3.9-fold (mean 0.61; CI 0.44 0.77 ) relative to healthy control subjects (mean 0.16; CI 0.09-0.22). The 'EMD-lysis' of $50 \mathrm{kDa}$ in chronic periodontitis was on average 4.4-fold (mean intensity value 3.08; CI 2.60 -
3.56), in aggressive periodontitis 2.2fold (mean 1.55, CI 1.11-2.00) and in gingivitis 3.3-fold (mean 2.32; CI 1.872.78) relative to healthy control subjects (mean 0.70; CI 0.44-0.96). The 'EMD-lysis' of $37 \mathrm{kDa}$ in chronic periodontitis was on average 5.8-fold (mean intensity value 0.60 ; CI 0.44 0.76 ), in aggressive periodontitis 3.9fold (mean 0.40; CI 0.27-0.53) and in gingivitis 3.3 -fold (mean 0.35 ; CI 0.26 $0.44)$ realtive to healthy control subjects (mean 0.10; CI 0.06-0.14). It is also notable that in all study groups there were samples with no observed EMD-degrading activity, but fewer in diseased groups (Fig. 1B-D).

To further determine the EMDdegrading proteases observed in periodontal gingival crevicular fluid, we studied the effects of recombinant
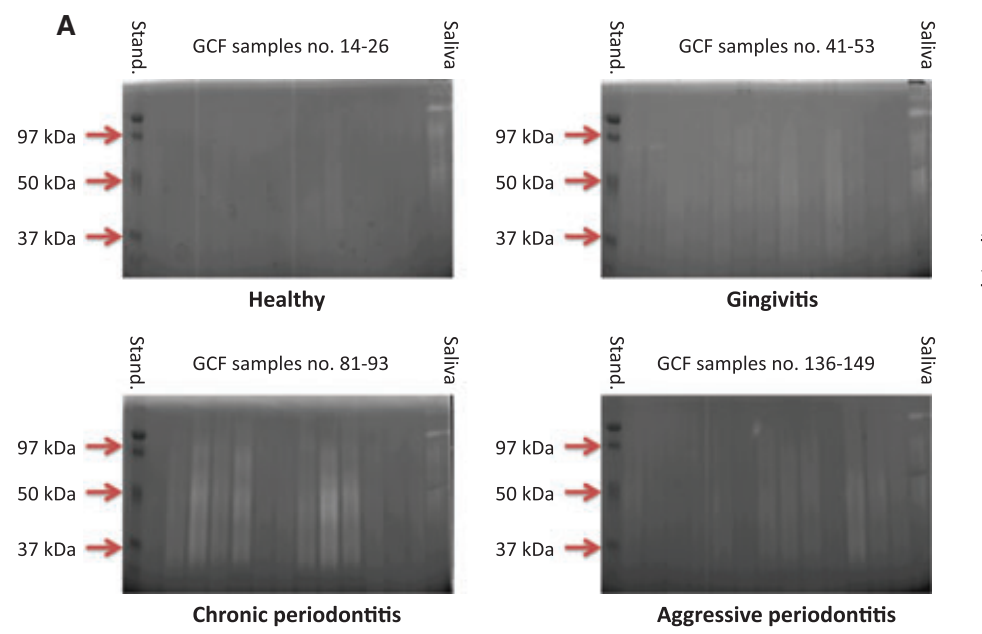

EMD degradation by GCF, $50 \mathrm{kDa}$

B

EMD degradation by GCF, $37 \mathrm{kDa}$

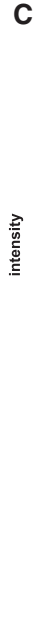

D
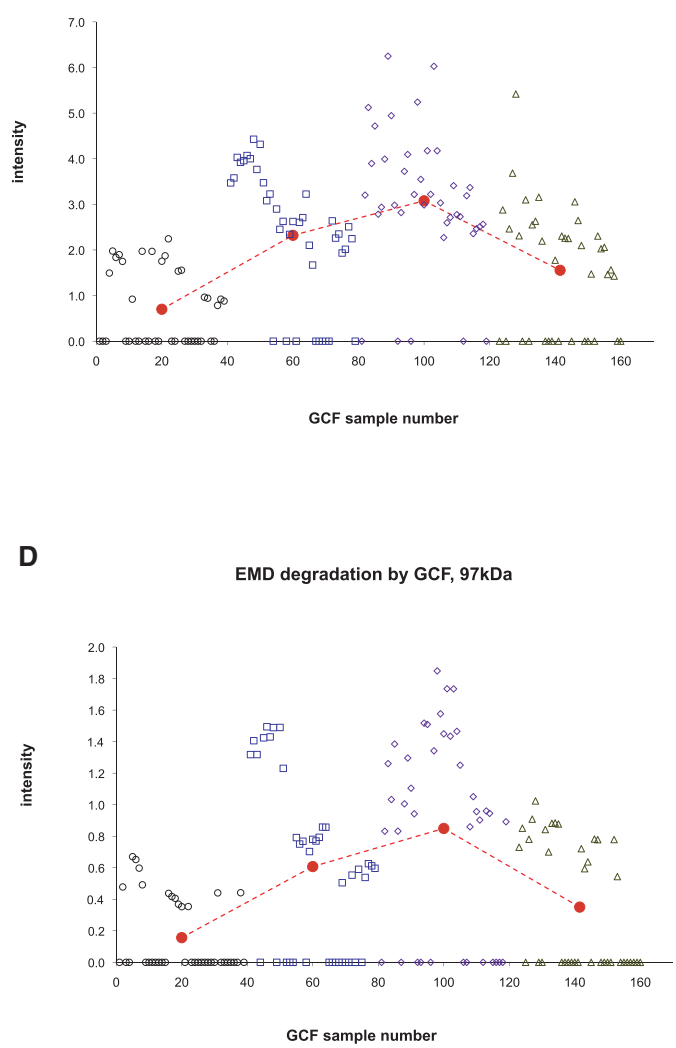

Fig. 1. Gingival crevicular fluid-induced degradation of Emdogain. In order to detect Emdogain-degrading effects of 156 gingival crevicular fluid samples obtained from subjects with different states of periodontal disease and healthy control subjects, the samples ( $15 \mu \mathrm{L}$ per well) were loaded onto EMD-embedded zymography (example gels, A). The intensities of the bands were measured at the most degraded sites at 97 , 50 and $37 \mathrm{kDa}$. The degradation depended on the state of periodontal disease, but the degradation was statistically more significant in all states of disease compared with the healthy control samples (B-D). The graphs (B-D) show individual scanning values of every gingival crevicular fluid sample (open symbols; $n=39$ per group) and group means (red dots joined with a dashed line). 
human MMP-1, -2, -8, -9, -13 and -14 on EMD-embedded gels. Only MMP-2 and MMP-8 produced barely detectable lysis of the gel and the bands

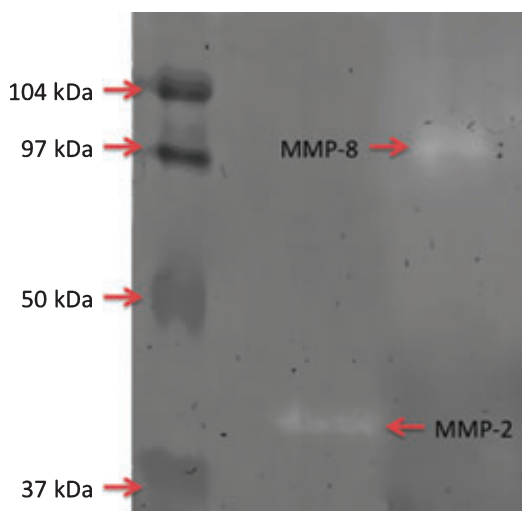

Fig. 2. Matrix metalloproteinase (MMP)2- and MMP-8-induced degradation of Emdogain. To determine the role of MMPs on the degradation of EMD, recombinant human MMPs were loaded ( $200 \mathrm{ng}$ in $3 \mu \mathrm{L}$ per well) onto EMD-embedded gel. Only MMP-2 and MMP-8 caused barely detectable lysis of the gel. were within a restricted range of molecular weights (Fig. 2).

\section{Proliferation assay}

The proliferation of periodontal ligament fibroblasts was remarkably induced by EMD after $48 \mathrm{~h}$ of incubation (Fig. 3). The induced proliferation was on average $24 \%$ higher with EMD at a concentration of $100 \mu \mathrm{g} /$ $\mathrm{mL}$, corresponding to a mean ELISA intensity of 0.62 (CI $0.60-0.64$ ) and $30 \%$ higher (mean 0.65 ; CI $0.62-0.68$ ) with EMD at a concentration of $200 \mu \mathrm{g} / \mathrm{mL}$ relative to control fibroblasts (mean 0.50; CI 0.48-0.52).

When EMD was incubated together with pooled and sterile filtered gingival crevicular fluid $(10 \mu \mathrm{g} / \mathrm{mL})$, the induction by EMD of the proliferation of periodontal ligament fibroblasts was decreased compared with treatment of cells using EMD alone (Fig. 3). Emdogain at a concentration of $200 \mu \mathrm{g} /$ $\mathrm{mL}$ together with gingival crevicular fluid still increased the proliferation of fibroblasts statistically significantly by $12 \%$ (mean 0.56; CI 0.54-0.58). However, EMD at the lower concentration of $100 \mu \mathrm{g} / \mathrm{mL}$ together with gingival crevicular fluid induced the proliferation by $6 \%$ only, which was not significant (mean 0.53; CI 0.51-0.55) relative to the control fibroblasts. Gingival crevicular fluid $(10 \mu \mathrm{g} / \mathrm{mL})$ alone, without EMD, had no effect on the proliferation of periodontal ligament fibroblasts (data not shown).

No differences in proliferation were found between control and amelogenintreated cells at a lower amelogenin concentration of $100 \mu \mathrm{g} / \mathrm{mL}$ (mean ELISA intensity 0.50 ; CI $0.47-0.53$ ). However, amelogenin at a higher concentration had a statistically significant inhibitory effect on the proliferation of periodontal ligament fibroblasts. On average, $200 \mu \mathrm{g} / \mathrm{mL}$ amelogenin implied a $54 \%$ decrease (mean 0.23 ; CI $0.22-0.25$ ) in the proliferation of periodontal ligament fibroblasts relative to control cells (Fig. 3).

\section{Discussion}

Our primary aim was to investigate the effects of gingival crevicular fluid on EMD. With EMD-embedded zymography, we observed that gingival crevicular fluid can, depending on the severity of the periodontal status, degrade EMD. Furthermore, we studied whether MMPs are mainly responsible for EMD degradation. However, based on our results, MMPs are not the main factors contributing to the observed degradation, and other proteases in gingival crevicular fluid are likely to be more important for the degradation of EMD in vivo. We also examined whether the gingival crevicular fluidinduced degradation of EMD has in vitro effects on the proliferation of periodontal ligament fibroblasts. The proliferation assay showed that gingival crevicular fluid depressed the proliferative effects of EMD on periodontal ligament fibroblasts. Furthermore, amelogenin did not show proliferative activity, as EMD did alone. Amelogenin at a concentration of $200 \mu \mathrm{g} / \mathrm{mL}$ was observed to decrease the proliferation of periodontal ligament fibroblasts, indicating that amelogenin alone 
is not the proliferative component of EMD, thereby showing that other growth factor-like components of EMD might be mainly responsible for the proliferative effect of EMD on periodontal ligament fibroblasts.

In this study, we had a considerably large number of gingival crevicular fluid samples in four subgroups: healthy, gingivitis, chronic periodontitis and aggressive periodontitis. Some degree of EMD degrading activity was observed in all study groups, but significantly more in the three diseased states compared with the healthy state. Furthermore, a larger variation in degradation was observed in diseased states than in healthy samples. This may reflect the fact that healthy gingival crevicular fluid is quite homologous, containing mainly plasma components and normal tissue turnover-related proteins (38). However, the protein content of gingival crevicular fluid obtained from periodontally affected sites is different, containing more proteolytic enzymes and also proteins of non-plasma origin (38). In the present study, we loaded the same volume of gingival crevicular fluid in the gels for each gingival crevicular fluid sample, so the samples from periodontal diseased sites may contain more proteins than those from healthy subjects. However, since the in vivo gingival crevicular fluid volume is larger in disease, the approach of using the same volume of gingival crevicular fluid instead of the same protein amount was selected as the study method, and it may be more analogous to the in vivo circumstances.

The transition from a healthy state to periodontal disease is characterized by proteolytic tissue destruction. The proteolytic enzymes can be both host derived and bacteria derived (39). Initiation of periodontal degradation starts with the release of products from the bacteria. All of the periodontopathogens, in particular Porphyromonas gingivalis, Aggregatibacter actinomycetemcomitans and Treponema denticola, can produce proteolytic enzymes capable of reducing the effectiveness of host defence, degrading host tissues and activating host proMMPs (40-42). However, most tissue destruction in periodontitis is mediated by host-derived proteolytic enzymes produced by sulcular epithelial cells, gingival fibroblasts, polymorphonuclear leukocytes and macrophages $(18,20,21)$. These proteases released in gingival tissues and gingival crevicular fluid include metallo-, serine- and cysteine- proteinases $(19,20,43-45)$. In particular, elevated levels of matrix metalloproteinase-1, -8 and -13 (collagenases) and MMP-2 and -9 (gelatinases) have been shown to correlate with periodontal disease activity $(19,20)$. Interestingly, both metalloendoproteinase and serine protease activity have also been observed in EMD itself (46). Furthermore, EMD has been shown to have effects on the MMP levels of many cell types. Emdogain can induce a more than threefold increase in MMP-2 levels produced by periodontal ligament fibroblasts and activate the collagenase, MMP-1, in MG-63 bone-derived cells $(47,48)$. We have previously shown that EMD can enhance MMP-2 and -9 production by HSC-3 carcinoma cells (27). Contrary to these findings, EMD has decreased the levels of MMP-1 and MMP-8 in gingival crevicular fluid after flap surgery in vivo (49). Since MMPs have a central role in periodontitis-induced proteolysis and EMD has been shown to be capable of regulating MMP production both in vitro and in vivo, out of the many proteolytic enzymes present in gingival crevicular fluid, we decided to study the effect of collagenases and gelatinases on the degradation of EMD. In this study, the degrading effects of MMPs on EMD-gel were limited and may be due to autolysis of the recombinant human MMPs. Thus, it seems possible that other proteolytic enzymes in gingival crevicular fluid are mainly responsible for the EMD degradation. Since the degradation caused by gingival crevicular fluid was notable over a wide range of molecular weights, it is likely that several enzymes, including certain MMPs, are acting together or even in cascade.

Emdogain consists mainly of amelogenin $(>90 \%)$, but it has been documented also to contain cytokines. Studies have found the presence of
TGF- $\beta 1$ or TGF- $\beta$-like substances, a BMP-like growth factor and bone sialoprotein-like molecules in EMD (11-14). Our study confirms the previous results showing that EMD can stimulate the proliferation of periodontal ligament fibroblasts in vitro (8,29-34). However, the recombinant amelogenin protein $(200 \mu \mathrm{g} / \mathrm{mL})$ was observed to depress the proliferation of periodontal ligament fibroblasts significantly. These observations suggest, as Chong et al. (7) have previously postulated, that amelogenin itself has very little to do with the proliferation of periodontal ligament fibroblasts, and that the stimulatory effect of EMD on the proliferation of periodontal ligament fibroblasts is caused by other factors in EMD.

In vivo, EMD has been shown to be capable of stimulating periodontal ligament regeneration in inflamed tissues $(2,3)$. However, we observed in vitro that EMD together with gingival crevicular fluid was less effective in promoting the proliferation than EMD alone, and with the lower concentration of EMD $(100 \mu \mathrm{g} / \mathrm{mL})$ the proliferation was not different from that of the control cells. These results suggest that gingival crevicular fluid can degrade or inactivate the growth factor-like molecules in EMD responsible for proliferation. It should also be noted that due to the high consumption of gingival crevicular fluid in these assays, we had to pool the gingival crevicular fluid samples and thus the assay also contained less effective EMD-degrading gingival crevicular fluid from healthy subjects. Therefore, it may be possible that gingival crevicular fluid obtained exclusively from patients with periodontal disease can decrease the proliferation even more than pooled gingival crevicular fluid. Within the limits of this in vitro study, it may be suggested that to achieve the best proliferative effect of EMD on periodontal fibroblasts and therefore the best regenerative effect, it is advisable to make the infection control phase of the treatment properly before EMD application to decrease inflammation and the EMD degrading proteases present in inflamed tissues and fluids. However, further studies are needed to achieve a more precise picture of the degradation 
of EMD in vivo and possibly to find ways for promoting the regenerative effects of EMD. To achieve this goal, in vitro studies of the effects of other proteolytic enzymes, in addition to MMPs, on the degradation of EMD would also be useful.

In conclusion, in this in vitro study we have shown for the first time that gingival crevicular fluid is capable of degrading EMD, depending on the periodontal status. Matrix metalloproteinase-2 and 8 were also found to be able to degrade EMD to a minor extent. Furthermore, gingival crevicular fluid can decrease EMD-induced proliferation of periodontal ligament fibroblasts.

\section{Acknowledgements}

The skilful technical assistance of Ms Maija-Leena Lehtonen (at the University of Oulu) is greatly appreciated. This study was supported by grants from the Academy of Finland, the Helsinki University Central Hospital Research Foundation, the Oulu University Central Hospital Research Foundation and the Finnish Dental Society Apollonia. We ensure that none of the authors have any financial or personal relationships with other people or organizations that could inappropriately influence our work.

\section{References}

1. Hammarström L. Enamel matrix, cementum development and regeneration. J Clin Periodontol 1997;24:658-668.

2. Sculean A, Schwarz F, Becker J, Brecx M. The application of an enamel matrix protein derivative (Emdogain) in regenerative periodontal therapy: a review. Med Princ Pract 2007;16:167-180.

3. Venezia E, Goldstein M, Boyan BD, Schwartz Z. The use of enamel matrix derivative in the treatment of periodontal defects: a literature review and metaanalysis. Crit Rev Oral Biol Med 2004; 15:382-402.

4. Gestrelius S, Lyngstadaas SP, Hammarström L. Emdogain - periodontal regeneration based on biomimicry. Clin Oral Investig 2000;4:120-125.

5. Zeichner-David M. Is there more to enamel matrix proteins than biomineralization? Matrix Biol 2001;20:307-316.

6. Hoang AM, Klebe RJ, Steffensen B, Ryu $\mathrm{OH}$, Simmer JP, Cochran DL. Amelogenin is a cell adhesion protein. J Dent Res 2002;81:497-500.
7. Chong $\mathrm{CH}$, Carnes DL, Moritz AJ et al. Human periodontal fibroblast response to enamel matrix derivative, amelogenin, and platelet-derived growth factor-BB. J Periodontol 2006;77:1242-1252.

8. Gestrelius S, Andersson C, Lidstrom D, Hammarstrom L, Somerman M. In vitro studies on periodontal ligament cells and enamel matrix derivative. J Clin Periodontol 1997;24:685-692.

9. Newman SA, Coscia SA, Jotwani R, Iacono VJ, Cutler CW. Effects of enamel matrix derivative on Porphyromonas gingivalis. J Periodontol 2003;74:11911195.

10. Kawase T, Okuda K, Yoshie H, Burns DM. Cytostatic action of enamel matrix derivative (EMDOGAIN) on human oral squamous cell carcinoma-derived SCC25 epithelial cells. J Periodont Res 2000; 35:291-300.

11. Kawase T, Okuda K, Momose M, Kato Y, Yoshie H, Burns DM. Enamel matrix derivative (EMDOGAIN) rapidly stimulates phosphorylation of the MAP kinase family and nuclear accumulation of $\operatorname{smad} 2$ in both oral epithelial and fibroblastic human cells. J Periodont Res 2001;36:367376.

12. Kawase T, Okuda K, Yoshie H, Burns DM. Anti-TGF-beta antibody blocks enamel matrix derivative-induced upregulation of $\mathrm{p} 21 \mathrm{WAF} 1 / \mathrm{cip} 1$ and prevents its inhibition of human oral epithelial cell proliferation. J Periodont Res 2002; 37:255-262.

13. Suzuki S, Nagano T, Yamakoshi Y et al. Enamel matrix derivative gel stimulates signal transduction of BMP and TGFbeta. J Dent Res 2005;84:510-514.

14. Iwata $\mathrm{T}$, Morotome $\mathrm{Y}$, Tanabe $\mathrm{T}$, Fukae M, Ishikawa I, Oida S. Noggin blocks osteoinductive activity of porcine enamel extracts. J Dent Res 2002;81:387-391.

15. Uitto VJ, Raeste AM. Activation of latent collagenase of human leukocytes and gingival fluid by bacterial plaque. $J$ Dent Res 1978;57:844-851.

16. Uitto VJ, Appelgren R, Robinson PJ. Collagenase and neutral metallo-proteinase activity in extracts of inflamed human gingiva. J Periodont Res 1981;16:417-424.

17. Sorsa T, Suomalainen K, Uitto VJ. The role of gingival crevicular fluid and salivary interstitial collagenases in human periodontal diseases. Arch Oral Biol 1990;35:193-196.

18. Birkedal-Hansen H. Role of cytokines and inflammatory mediators in tissue destruction. J Periodont Res 1993;28:500-510.

19. Sorsa T, Tjäderhane L, Salo T. Matrix metalloproteinases (MMPs) in oral diseases. Oral Dis 2004;10:311-318.

20. Sorsa T, Tjäderhane L, Konttinen YT et al. Matrix metalloproteinases: contribution to pathogenesis, diagnosis and treatment of periodontal inflammation. Ann Med 2006;38:306-321.

21. Birkedal-Hansen H, Moore WG, Bodden MK et al. Matrix metalloproteinases: a review. Crit Rev Oral Biol Med 1993;4: 197-250.

22. Nagase H, Woessner JF Jr. Matrix metalloproteinases. J Biol Chem 1999; 274:21491-21494.

23. Gestrelius S, Andersson C, Johansson AC et al. Formulation of enamel matrix derivative for surface coating. Kinetics and cell colonization. J Clin Periodontol 1997;24:678-684.

24. Armitage GC. Development of a classification system for periodontal diseases and conditions. Ann Periodontol 1999;4:1-6.

25. Saxer UP, Mühlemann HR. Motivation und Aufklärung. SSO Schweiz Monatsschr Zahnheilkd 1975;85:905-919.

26. Ryu OH, Fincham $\mathrm{AG}, \mathrm{Hu} \mathrm{CC}$ et al. Characterization of recombinant pig enamelysin activity and cleavage of recombinant pig and mouse amelogenins. $J$ Dent Res 1999;78:743-750.

27. Laaksonen M, Suojanen J, Nurmenniemi S, Läärä E, Sorsa T, Salo T. The enamel matrix derivative (Emdogain) enhances human tongue carcinoma cells gelatinase production, migration and metastasis formation. Oral Oncol 2008;44:733-742.

28. Laemmli UK. Cleavage of structural proteins during the assembly of the head of bacteriophage T4. Nature 1970;227: 680-685.

29. Cattaneo V, Rota C, Silvestri M et al. Effect of enamel matrix derivative on human periodontal fibroblasts: proliferation, morphology and root surface colonization. An in vitro study. $J$ Periodontol 2003;38:568-574.

30. Davenport DR, Mailhot JM, Wataha JC, Billman MA, Sharawy MM, Shrout MK. Effects of enamel matrix protein application on the viability, proliferation, and attachment of human periodontal ligament fibroblasts to diseased root surfaces in vitro. J Clin Periodontol 2003;30:125-131.

31. Okubo K, Kobayashi M, Takiguchi T et al. Participation of endogenous IGF-I and TGF-beta 1 with enamel matrix derivative-stimulated cell growth in human periodontal ligament cells. J Periodontol 2003;38:1-9.

32. Rincon JC, Haase HR, Bartold PM. Effect of Emdogain ${ }^{\circledR}$ on human periodontal fibroblasts in an in vitro woundhealing model. J Periodont Res 2003; 38:290-295.

33. Rodrigues TL, Marchesan JT, Coletta RD et al. Effects of enamel matrix derivative and transforming growth factor-betal on human periodontal ligament fibroblasts. J Clin Periodontol 2007;34:514-522.

34. Zeldich E, Koren R, Nemcovsky C, Weinreb M. Enamel matrix derivative 
stimulates human gingival fibroblast proliferation via ERK. J Dent Res 2007; 86:41-46.

35. Oikarinen K, Seppa S. Effect of preservation media on proliferation and collagen biosynthesis of periodontal ligament fibroblasts. Endod Dent Traumatol 1987; 3:95-99.

36. Heikkilä P, Suojanen J, Pirilä E et al. Human tongue carcinoma growth is inhibited by selective antigelatinolytic peptides. Int J Cancer 2006;118:22022209.

37. Sterne J, Davey Smith G. Shifting the evidence - what's wrong with significance tests. BMJ 2001;322:226-231.

38. Curtis MA, Sterne JA, Price SJ et al. The protein composition of gingival crevicular fluid sampled from male adolescents with no destructive periodontitis: baseline data of a longitudinal study. $J$ Periodont Res 1990;25:6-16.

39. Sandholm L. Proteases and their inhibitors in chronic inflammatory periodontal disease. J Clin Periodontol 1986; 13:19-26.
40. Potempa J, Banbula A, Travis J. Role of bacterial proteinases in matrix destruction and modulation of host responses. Periodontol 2000 2000;24:153-192.

41. Eley BM, Cox SW. Proteolytic and hydrolytic enzymes from putative periodontal pathogens: characterization, molecular genetics, effects on host defenses and tissues and detection in gingival crevice fluid. Periodontol 2000 2003;31:105-124.

42. Ding Y, Uitto VJ, Firth J et al. Modulation of host matrix metalloproteinases by bacterial virulence factors relevant in human periodontal diseases. Oral Dis 1995;1:279-286.

43. Eley BM, Cox SW. Cathepsin B/L-, elastase-, tryptase-, trypsin- and dipeptidyl peptidase IV-like activities in gingival crevicular fluid: a comparison of levels before and after periodontal surgery in chronic periodontitis patients. $J$ Periodontol 1992;63:412-417.

44. Palcanis KG, Larjava IK, Wells BR et al. Elastase as an indicator of periodontal disease progression. J Periodontol 1992; 63:237-242.
45. Lah TT, Babnik J, Schiffmann E, Turk V, Skaleric U. Cysteine proteinases and inhibitors in inflammation: their role in periodontal disease. J Periodontol 1993; 64:485-491.

46. Maycock J, Wood SR, Brookes SJ, Shore RC, Robinson C, Kirkham J. Characterization of a porcine amelogenin preparation, EMDOGAIN, a biological treatment for periodontal disease. Connect Tissue Res 2002;43:472-476.

47. Mirastschijski U, Konrad D, Lundberg E, Lyngstadaas SP, Jorgensen LN, Agren MS. Effects of a topical enamel matrix derivative on skin wound healing. Wound Repair Regen 2004;12:100-108.

48. Goda S, Inoue H, Kaneshita Y et al. Emdogain stimulates matrix degradation by osteoblasts. J Dent Res 2008;87:782-787.

49. Okuda K, Miyazaki A, Momose M et al. Levels of tissue inhibitor of metalloproteinases-1 and matrix metalloproteinases- 1 and -8 in gingival crevicular fluid following treatment with enamel matrix derivative (EMDOGAIN). $J$ Periodont Res 2001;36:309-316. 